\title{
Comparison Groups in Autism Family Research: Down Syndrome, Fragile X Syndrome, and Schizophrenia
}

\author{
Marsha Mailick Seltzer, ${ }^{1,3}$ Leonard Abbeduto, ${ }^{1}$ Marty Wyngaarden Krauss, ${ }^{2}$ \\ Jan Greenberg, ${ }^{1}$ and April Swe ${ }^{1}$
}

This paper examines methodological challenges inherent in conducting research on families of children with autism and in comparing these families with others who are coping with different types of disabilities or who have nondisabled children. Although most comparative research has contrasted families whose child has autism with those whose child has Down syndrome, the range of comparison groups can be expanded to offer additional points of contrast and control. We discuss both matching and statistical control procedures and point to next steps in this line of comparative autism family research.

KEY WORDS: Autism; Down syndrome; families; fragile X; matching; schizophrenia.

\section{INTRODUCTION}

This paper focuses on comparative research about families who have a member with autism. We specifically focus on the goals of, and methodological challenges inherent in, conducting group comparisons in research investigating family influences on children with autism and, reciprocally, of children on families. Although a great deal can be learned from within-group analyses of family functioning, comparative research offers the opportunity to examine the extent to which family functioning in the context of autism differs from or is similar to family functioning in the context of other disorders. By mapping the territory of similarities and differences, comparative research can increase our understanding of how the unique characteristics of autism affect the family and how the family affects the

\footnotetext{
${ }^{1}$ Waisman Center, University of Wisconsin-Madison, Madison, Wisconsin 53705.

${ }^{2}$ Heller School, Brandeis University, Waltham, Massachusetts 02454 .

${ }^{3}$ Correspondence should be addressed to Dr. Marsha Mailick Seltzer, Waisman Center, University of Wisconsin-Madison, 1500 Highland Avenue, Madison WI 53705-2280; e-mail: mseltzer@waisman .wisc.edu
}

manifestation of the symptoms of autism over the life course.

Researchers have articulated a number of considerations regarding the factors on which individuals with autism should be matched or otherwise equated. The point has been made that, without appropriate comparison groups, it is difficult to know whether the deficits that are identified in children with autism are unique to this disorder or common to developmental disabilities in general (Burack, Iarocci, Bowler, \& Mottron, 2002; Tager-Flusberg, 1999). Furthermore, it has been noted that there are advantages of including comparisons with children who do not have disabilities; namely, to reveal strengths as well as weaknesses in children with autism (Hodapp \& Dykens, 2001). These same points apply to questions of matching or equating groups of families who have a child with autism versus other groups, although the relevant matching or control variables might differ in the family versus the individual context.

In the next section, the findings of comparative family studies are briefly summarized. We review the types of group comparisons that have been used and the range of outcomes reported. This review provides a context for our subsequent discussion of methodological issues that should be considered in comparative 
studies. These issues include the strengths and limitations of different approaches to controlling group differences and the benefits of using two new comparison groups that have not been widely included in autism family research. We conclude with a brief examination of next steps for future investigations.

\section{FINDINGS FROM COMPARATIVE STUDIES OF FAMILIES}

There is a long history of comparative research on families who have young child with autism. Nearly 30 years ago, Holroyd and McArthur (1976) compared levels of stress among mothers of young children with autism to those of mothers of young children with Down syndrome and mothers of children evaluated in a clinic setting (some of whom had mental retardation). They reported that in comparison to mothers of children with Down syndrome, mothers of children with autism were more upset and disappointed with their child; more concerned about the child's dependency, behavior management needs, and effects of the child on the other family members; and more anxious about obtaining appropriate services. The durability of these findings about elevated levels of maternal stress has been demonstrated in more recent research (e.g., Bouma \& Schweitzer, 1990; Kasari \& Sigman, 1997). Studies that have compared both mothers and fathers of children with autism to parents of children with other diagnoses suggest that mothers are affected more negatively than fathers and that families of children with autism experience more problems than families of children with other diagnosed conditions (Dumas, Wolf, Fisman, \& Culligan, 1991; Fisman, Wolf, \& Noh, 1989; Rodrigue, Morgan, \& Geffken, 1990, 1992; Wolf, Noh, Fisman, \& Speechley, 1989). The comparative focus has also been extended to siblings of children with autism, who have been found to have higher levels of both internalizing and externalizing behavior problems and lower rates of social interaction with their brother or sister with autism than other groups (Fisman et al., 1996; Knott, Lewis, \& Williams, 1995; Rodrigue, Geffken, \& Morgan, 1993).

Only a few studies have focused on parental stress during the adolescent and adult periods; these have shown a similarly elevated pattern of stress as in families of young children with autism (e.g., Donovan, 1988). Holmes and Carr (1991) found that although three-quarters of the parents of adults with Down syndrome in their study said that their son or daughter was easier to care for as an adult than as a child, almost half of the parents of adults with autism described their child as more difficult to care for at this stage of life.

Several features of these comparison studies warrant comment. First, the sample sizes in all the studies are small (generally under 30 participants per diagnostic group) and nonrandomly selected, thereby limiting the generalizability of the results. Second, most were conducted with parents of young children and preadolescents (usually under age 12). Third, the consistency of the contrast between parents of children with autism and parents of contrast group children is remarkable, with parents of children with autism reporting higher levels of distress and a more distant relationship with their child in all studies.

An underlying and unanswered question pertains to the cause of the consistent group differences reported in these studies. The working hypothesis in most studies is that observed differences among parents or siblings are the result of differences in the behavioral phenotype of the child with autism versus that of the child in the comparison group(s). But other factors can confound such group differences, including differences in child characteristics (e.g., birth order, gender), family sociodemographic characteristics (e.g., race/ethnicity, income, number of children, parental marital status), and biological or psychological vulnerabilities (e.g., the broader autism phenotype) of the family members of individuals with autism versus the family members in the comparison groups. In comparative family research, a critical design consideration is whether the groups should be matched on key child and/or family characteristics to control for such differences or, alternatively, whether statistical techniques should be used to expose the influence of such variables. One or both of these approaches is exemplified in most of the studies reviewed to this point. In the next section, we examine these issues.

\section{CONTROLLING FOR OR EVALUATING CONFOUNDING VARIABLES}

If the goal of a comparison study is to identify outcomes in family members that are attributable to the unique conditions associated with raising (in the case of parents) or being raised with (in the case of siblings) a child who has autism, it is crucial that the effects of other potential confounding factors be controlled or evaluated. Such effects can be addressed through matching during participant selection or subsequently 
through statistical means. Although matching and statistical control are not equivalent, they share the same goal; namely, controlling the variance associated with potentially confounding between-group differences. There may be situations in which matching is preferable to statistical control (such as in small samples where there would be insufficient variability for the latter approach) whereas other instances, such as largescale surveys, may lend themselves to statistical control to address extraneous sources of variation across groups.

\section{Child Characteristics}

Most comparative studies of families of children with autism match on or control for child characteristics. Nearly every study reviewed earlier matched or controlled child chronological age. The assumption here is that there are various dynamics within the family that typically vary with age-related changes in, and societal expectations for, the child with autism. Child gender is often a matching variable (e.g., Dissanayke \& Crossley, 1996; Dumas et al., 1991; Fisman et al., 1989, 1996; Kasari \& Sigman, 1997; Rodrigue et al., 1990, 1992; Wolf et al., 1989). This is sensible in light of well-documented differences in parental behavior and expectations tied to child gender (Leaper, 2002). Moreover, gender matching is particularly important given the preponderance of males in the population with autism as compared to many other types of developmental disabilities (DSM-IV, 2000). Birth order, which can affect parental behavior and expectations, has also often been used as a matching variable, particularly in studies in which the contrast group has Down syndrome (e.g., Dissanayke \& Crossley, 1996; Kaminsky \& Dewey, 2001; Rodrigue et al., 1990, 1992; Roeyers \& Mycke, 1995). Interestingly, one study noted explicitly the difficulty of matching samples of children with autism and Down syndrome because of the disproportionate number of males in the population with autism and the disproportionately greater likelihood of being later in the birth order in the population with Down syndrome (Knott et al., 1995). Because there is good evidence that child characteristics, such as gender and birth order, affect parental and sibling well-being, the role of such characteristics must be controlled or evaluated. The effects of these child characteristics should be statistically controlled when the groups to be compared have different distributions of these characteristics. Although some researchers may prefer participant matching strategies, statistical control may be preferable if matching through participant selection leads to samples that are not representative of their respective diagnostic conditions.

\section{Family Sociodemographic Characteristics}

Other possible factors that warrant control in comparative studies of families of children with autism versus other diagnostic groups include family sociodemographic characteristics, such as race/ethnicity, socioeconomic status, number of children in the family, parental marital status, and parental age. These factors are important to control to the extent they have independent influences on dependent measures of family well-being and if they differ in their distribution across the comparison groups. In practice, however, family sociodemographic characteristics are less frequently controlled than child characteristics in comparative autism family research. Exceptions include socioeconomic status and race (Bagenholm \& Gillberg, 1991; Bristol, Gallagher, \& Schopler, 1988; Fisman et al., 1996; Kasari \& Sigman, 1997; Rodrigue et al., 1990, 1992, 1993). Recently, Blacher (2003) reported that Latina mothers of individuals with autism did not differ in their level of stress from Latina mothers whose child had other types of developmental disabilities, which contrasted with the characteristic pattern of elevated stress in mothers of individuals with autism that was evident in their Anglo and African American samples. This reinforces the need to consider race/ethnicity in comparison studies.

Age of family members other than the child with autism has also been controlled in comparative autism family research. In some studies of siblings, sibling age and/or age difference between the sibling with autism and the nondisabled sibling are controlled (Bagenholm \& Gillberg, 1991; Kaminsky \& Dewey, 2001, Rodrigue et al., 1993; Roeyers \& Mycke, 1995) whereas parental age is a focus in other studies (e.g., Bristol et al., 1988). Family size is particularly important because of its relation to birth order of the child with the disability (see Seltzer, Greenberg, Floyd, Pettee, \& Hong, 2001).

In summary, sociodemographic factors form the context in which families cope with the demands of parenting a child with autism. Race and ethnicity are important because there is some evidence that the cultural context may mediate or moderate the effect of the child's behavioral phenotype on maternal well-being. Age of individual family members is important because 
age is a marker of progression in the family life course, which too may affect individual and family outcomes.

\section{Familial Biological and Psychological Vulnerability}

The strongest evidence for a genetic basis of autism comes from twin studies that show a high concordance for autism in monozygotic twins (Folstein \& Rutter, 1977a, 1977b; Ritvo, Freeman, Mason-Brothers, Mo, \& Ritvo, 1985). Whereas approximately $60 \%$ of monozygotic twins are concordant for autism, more than $90 \%$ are concordant for other social or cognitive difficulties (Bailey et al., 1995). Additional support for a genetic basis of autism comes from the higher recurrence risk for siblings of $4.5 \%$ (Jorde et al., 1991) compared to the general population risk (less than 1\%). Indeed, parents and other family members of persons with autism may face a dual challenge: the demands of caring for the individual with autism and at the same time dealing with an elevated risk of language difficulties (Piven, Palmer, Jacobi, Childress, \& Arndt, 1997a; Piven et al., 1997b), social impairments (Piven et al., 1997a), learning disabilities (Bolton et al., 1994), cognitive disabilities (Boutin et al., 1997), and psychiatric disorders (Lainhart \& Folstein, 1994). Although elevations in these areas of difficulty might be the result of shared environmental influences, they are most often interpreted from a family genetics perspective (Bailey et al., 1998). To the extent that such vulnerabilities are independent contributors to differences between families of children with autism and families of children with other types of disabilities, such factors warrant control in comparative autism family research.

In comparative autism family research, the broader autism phenotype poses methodological challenges in sorting out prior predisposition and vulnerability to stress in parents and siblings from the subsequent effect of rearing or growing up with a child with a disability. If prior vulnerabilities influence subsequent parental and sibling psychopathology, betweendiagnostic group comparisons of the effects of a child with a disability on familial well-being may be at least in part the result of differential vulnerability rather than differences in the effects of the behavioral phenotypes of the children being compared. Thus far, this issue has not been widely addressed in autism family research. Indeed, there has been little dialogue between family researchers who study parental and sibling psychological well-being and the behavioral geneticists who have charted the contours of the broader autism phenotype.
Therefore, one critical challenge facing future comparative research is devising strategies for bringing measures of genetic vulnerability into the analysis of patterns of family coping and well-being.

\section{NEW OPPORTUNITIES FOR COMPARATIVE AUTISM FAMILY RESEARCH: FRAGILE $X$ SYNDROME AND SCHIZOPHRENIA}

As described earlier, the preponderance of published studies comparing families of children with autism to families whose children have other types of disorders have focused on Down syndrome as the comparison group. In many respects, Down syndrome is an ideal contrast with autism, given the comparative social and behavioral "advantage" characteristic of individuals with Down syndrome and the relative disadvantage of individuals with autism in these characteristics. However, Burack and colleagues (2001) have noted that a more informative matching strategy might include the use of more than one comparison group, with each comparison group matched to the target group on specific domains. For comparative family studies, diagnostic groups in addition to Down syndrome may offer new opportunities for drawing insights into what makes the family experience of autism unique. Two of these alternative comparison groups are fragile $X$ syndrome and schizophrenia. Although there have been a few past studies in which individuals with autism have been compared with individuals with fragile X syndrome (e.g., Bailey, Hatton, Mesibov, Ament, \& Skinner, 2000a), contrasts between families of individuals with autism and schizophrenia are rare. However, as described below, these two examples illustrate the fact that the selection of comparison groups can itself have the effect of controlling sources of variance that might otherwise confound the search for the effects of the unique conditions of autism on family well-being.

Three factors in particular illustrate the new insights that might be gleaned from comparative family studies involving families affected by autism, fragile $\mathrm{X}$, and schizophrenia. The first concerns the elevated genetic risk for family members of having some level of behavioral, cognitive, or psychiatric problems or limitations, as is characteristic of autism (the broader autism phenotype). Elevations in risk are also characteristic of families with children with fragile X syndrome (Franke et al., 1996; Hagerman, 1999; Keysor \& Mazzocco, 2002; Mazzocco, 2000) and schizophrenia 
(Asarnow et al., 2001; Krabbendam, Marcelis, Delespaul, Joiles, \& Van Os, 2001; Tsuang, Stone, \& Faraone, 2002). Such elevated risks are not present in families whose child has Down syndrome nor systematically in heterogeneous comparison groups of families of children with mental retardation due to unknown causes. Although the comparative magnitude of the genetic risk of autism, fragile $\mathrm{X}$ syndrome, and schizophrenia is difficult to assess, the documented elevation in risk in all three of these groups makes them more similar to each other than they are to groups of families with no genetic vulnerability. Thus, by comparing families whose child has autism to families of individuals with fragile $\mathrm{X}$ syndrome or schizophrenia, some control of familial genetic vulnerability is introduced into the research design, although there are distinct patterns of vulnerability in each of these groups.

Other factors that can be clarified by including families with a child with fragile $\mathrm{X}$ syndrome or schizophrenia in comparative autism family research concern the timing of the diagnosis of the child in the family life course and the certainty of the diagnosis. Whereas families whose child has Down syndrome are aware of this diagnosis at birth (and sometimes even before birth), this is not the case in autism, which is generally not diagnosed until between age 3 and 4 (Yeargin-Allsopp et al., 2003). Furthermore, whereas Down syndrome is a certain diagnosis, confirmed by genetic testing, the diagnosis of autism is ambiguous because it relies on behavioral criteria and in some cases remains uncertain in the eyes of families throughout the life course. Thus, differences between families whose child has autism versus Down syndrome may arise in part because of the certainty and immediacy of the diagnosis of Down syndrome as compared with the ambiguity of the autism diagnosis and the longer duration before the diagnosis is made. These issues cannot be sorted out in studies comparing families of children with autism and families of children with Down syndrome because of the complete confounding of the timing and certainty of the diagnosis with type of disability.

However, by including families with a child with fragile X syndrome and families whose child has schizophrenia in the research design, the effect of variation in both timing and certainty of the child's diagnosis on familial well-being can be investigated. As with autism, fragile $\mathrm{X}$ syndrome is generally not diagnosed (at least in the first affected child in the family) until age 3 or older (Bailey, Skinner, Hatton, \& Roberts, 2000b; Poehlmann, Clements, Farsad, \& Abbeduto, 2003) whereas schizophrenia is not diagnosed until later adolescence and young adulthood (DSM-IV, 2000). Also, schizophrenia shares with autism the feature of being a diagnosis derived by an analysis of behaviors and symptoms that cannot currently be confirmed by genetic testing. Thus, by including these groups of families in comparative autism family research, it may be possible to examine how the "diagnostic odyssey" and its timing in the family life course contribute to the pattern of stress, coping, and well-being manifested by family members. Uncontrolled, these factors can confound the effects of the behavioral phenotype on family well-being.

Two recently conducted studies illustrate the value of adding these comparison groups to studies of families of individuals with autism. In one study, Abbeduto et al. (2004) compared three groups of mothers: those whose adolescent or young adult son or daughter had autism, Down syndrome, or fragile X syndrome. The three groups were comparable in family socioeconomic status and child age whereas differences in child gender and family size were statistically controlled. Abbeduto et al. found that the three groups of mothers differed in their degree of pessimism about the child's future, perception of closeness in the mother-child relationship, and the percentage of those who scored in the clinical range of depression. In general, mothers of adolescents and young adults with Down syndrome reported the highest levels of psychological well-being and mothers of adolescents and young adults with autism the lowest levels, with mothers of those with fragile $\mathrm{X}$ syndrome generally being midway between the other two groups. The investigators also found that most of the differences between groups reflected differences in the number of behavioral symptoms displayed by the adolescent or young adult. They speculated that group differences in maternal well-being that were not explained by the set of predictors examined were due to unmeasured syndrome-specific differences in the children's behavioral profiles and family risk status.

In another study, Greenberg, Seltzer, Chou, Hong, and Krauss (2004) compared mothers of adults with autism, Down syndrome, and schizophrenia with respect to a variety of factors, including closeness in the relationship between the mother and the adult with disabilities, using the same measure of relationship quality as in the Abbeduto et al. study described above. Although the three groups were similar in the marital status of the mother, they differed in the age, gender, and health status of the adult, the mother's age, education, and whether she co-resided with her son or daughter with disabilities. Controlling for these background variables (child age 
was not controlled because of its high correlation with maternal age), Greenberg et al. found that a close relationship is more characteristic of dyads in which the adult had Down syndrome than autism or schizophrenia. They reported no difference in closeness between the autism or schizophrenia mother-adult dyads. Furthermore, the quality of the mother-adult relationship was highly predictive of maternal depression in families in which the adult had autism or schizophrenia but not in families in which the adult had Down syndrome, even when sociodemographic factors and aspects of the behavioral phenotype were controlled. This unexpected finding warrants additional investigation, but there are two possible explanations. First, there may have been insufficient variability in the relationship quality measure in the sample with Down syndrome. Alternatively, aspects of familial vulnerability (i.e., the broader autism phenotype and its analog in families whose adult has schizophrenia) may have increased the sensitivity and reactivity of the mother to the quality of her relationship with her adult child.

These two examples illustrate the value of including diagnostic groups other than Down syndrome in comparative autism family research. The range of comparative hypotheses can be broadened and the contours of the unique family reaction to the behavioral profile of autism can be more sharply delineated.

\section{IDENTIFICATION OF DIFFERENCES IN FAMILY COMPARISONS: THE END OR THE BEGINNING?}

Once differences have been identified between the families of children with autism and one or more comparison groups and plausible confounding variables have been eliminated as explanations of those differences, then what? Whereas some investigators see the demonstration of such differences as the ultimate goal of their research, we do not. Simply finding and reporting differences does not provide an explanation for those differences. What is it about autism that leads to such differences in the well-being of family members? Are these differences the results of the challenging behaviors unique to the child with the diagnosis of autism? If so, which behaviors and how do those behaviors produce their effects in parents or other family members? In addition, there may be challenges that are common among individuals with autism but that are shared with other diagnostic conditions (e.g., language delays) that have adverse consequences for other family members. Alternatively, the differences may reflect the operation of contextual factors rather than those specific to the characteristics of the child with autism. It may be that uncertainty surrounding the diagnosis of autism, the nature of the supports available (or not available), or the stigma associated with the diagnosis in our culture contribute to the differential effects observed in family members. It might also be that the effects reflect the broader autism phenotype in those family members either alone or in combination with the stress of raising a challenging child and the particular contextual factors associated with that life-long process. In short, group comparisons in family research should be the start, not the end, of the line of inquiry into understanding the impact of autism on the family.

\section{ACKNOWLEDGMENTS}

Support for the preparation of this manuscript was provided by grants from the National Institute on Aging (R01 AG08768), National Institute of Child Health and Human Development (R01 HD24356), and the National Institute of Mental Health (R01 MH55928).

\section{REFERENCES}

Abbeduto, L., Seltzer, M. M., Shattuck, P. T., Krauss, M. W., Orsmond, G. I., \& Murphy, M. (2004). Psychological well-being and coping in mothers of adolescents and young adults with developmental disabilities: Comparisons between autism, Down syndrome, and fragile X syndrome. American Journal on Mental Retardation.

Asarnow, R. F., Neuchterlien, K. H., Fogelson, D., Subotnik, K. L., Payne, D. A., Russell, A. T., Asamen, J., Kuppinger, H., \& Kendler, K. S. (2001). Schizophrenia and schizophreniaspectrum personality disorders in the first-degree relatives of children with schizophrenia: The UCLA study. Archives of General Psychiatry, 58, 581-588.

Bagenholm, A., \& Gillberg, C. (1991). Psychosocial effects on siblings of children with autism and mental retardation: A population-based study. Journal of Mental Deficiency Research, $35,291-307$.

Bailey, A., Le Couteur, A., Gottesman, I., Bolton, P., Simonoff, E., Yuzda, E., \& Rutter, M. (1995). Autism as a strongly genetic disorder: Evidence from a British twin study. Psychological Medicine, 25, 63-78.

Bailey, A., Palferman, S., Heavey, L., \& Le Couteur, A. (1998). Autism: The phenotype in relatives. Journal of Autism and Developmental Disorders, 28, 369-392.

Bailey, D. B., Hatton, D. H., Mesibov, G., Ament, N., \& Skinner, M. (2000a). Early development, temperament, and functional impairment in autism and fragile X syndrome. Journal of Autism and Developmental Disorders, 30, 49-59.

Bailey, D. B., Skinner, D., Hatton, D., \& Roberts, J. (2000b). Family experiences and factors associated with the diagnosis of fragile $\mathrm{X}$ syndrome. Journal of Developmental and Behavioral Pediatrics, 21, 315-321. 
Blacher, J. (2003, May). Now: Increasingly diverse families: Do yesterday's findings apply? In L. M. Glidden (Chair), Bernard Farber memorial symposium on family research: Then, now, and not yet. Symposium conducted at the meeting of the Academy on Mental Retardation, Chicago, IL.

Bolton, P., Macdonald, H., Pickles, A., Rios, P., Goode, S., Crowson, M., Bailey, A., \& Rutter, M. (1994). A case-control family history study of autism. Journal of Child Psychology and Psychiatry and Allied Disciplines, 35, 877-900.

Bouma, R., \& Schweitzer, R. (1990). The impact of chronic childhood illness on family stress: A comparison between autism and cystic fibrosis. Journal of Clinical Psychology, 46, 722-730.

Boutin, P., Maziade, M., Merette, C., Mondor, M., Bedard, C., \& Thivierge, J. (1997). Family history of cognitive disabilities in first-degree relatives of autistic and mentally retarded children. Journal of Autism and Developmental Disorders, 27, 165-176.

Bristol, M. M., Gallagher, J. J., \& Schopler, E. (1988). Mothers and fathers of young developmentally disabled and non-disabled boys: Adaptation and spousal support. Developmental Psychology, 24, 441-451.

Burack, J., Pasto, L., Porporino, M., Iorocci, G., Mottron, L., \& Bowler, D. (2001). Applying developmental principles to the study of autism. In E. Schopler, N. Yirmiya, C. Shulman, \& L. M. Marcus (Eds.), The research basis for autism research (pp. 25-41). New York: Kluwer Academic/Plenum.

Burack, J. A., Iarocci, G., Bowler, D., \& Mottron, L. (2002). Benefits and pitfalls in the merging of disciplines: The example of developmental psychopathology and the study of persons with autism. Development and Psychopathology, 14, 225-237.

Diagnostic and statistical manual of mental disorders: DSM-IV-TR, 4th edition, text revision (2000). Washington, DC: American Psychiatric Association.

Dissanayake, C., \& Crossley, S. A. (1996). Proximity and sociable behaviors in autism: Evidence for attachment. Journal of Child Psychology, Psychiatry and Allied Disciplines, 37, 149-156.

Donovan, A. M. (1988). Family stress and ways of coping with adolescents who have handicaps: Maternal perceptions. American Journal on Mental Retardation, 92, 502-509.

Dumas, J. E., Wolf, L. C., Fisman, S. N., \& Culligan, A. (1991). Parenting stress, child behavior problems, and dysphoria in parents of children with autism, Down syndrome, behavior disorders, and normal development. Exceptionality, 2, 97-110.

Fisman, S. N., Wolf, L. C., \& Noh, S. (1989). Marital intimacy in parents of exceptional children. Canadian Journal of Psychiatry, 34, 519-525.

Fisman, S., Wolf, L., Ellison, D., Gillis, B., Freeman, T., \& Szatmari, P. (1996). Risk and protective factors affecting the adjustment of siblings of children with chronic disabilities. Journal of American Academy of Child and Adolescent Psychiatry, 35, $1532-1541$.

Folstein, S., \& Rutter, M. (1977a). Genetic influences and infantile autism. Nature, 265, 726-728.

Folstein, S., \& Rutter, M. (1977b). Infantile autism: A genetic study of 21 twin pairs. Journal of Child Psychology and Psychiatry and Allied Disciplines, 18, 297-321.

Franke, P., Barbe, B., Leboyer, M., \& Maier, W. (1996). Fragile X syndrome: II. Cognitive and behavioral correlates of mutations of the FMR-1 gene. European Psychiatry, 11, 233-243.

Greenberg, J., Seltzer, M. M., Chou, R., Hong, J., \& Krauss, M. W. (2004). The effect of quality of the relationship between mothers and adult children with disabilities: The mediating role of optimism. American Journal of Orthopsychiatry.

Hagerman, R. J. (1999). Neurodevelopmental disorders. Oxford: Oxford University Press.

Hodapp, R. M., \& Dykens, E. M. (2001). Strengthening behavioral research on genetic mental retardation syndromes. American Journal of Mental Retardation, 106, 4-15.
Holmes, N., \& Carr, J. (1991). The pattern of care in families of adults with a mental handicap: A comparison between families of autistic adults and Down syndrome adults. Journal of Autism and Developmental Disorders, 2, 159-176.

Holroyd, J., \& McArthur, D. (1976). Mental retardation and stress on the parents: A contrast between Down's syndrome and childhood autism. American Journal of Mental Deficiency, 80, 431-436.

Jorde, L., Hasstedt, S., Ritvo, E., Mason-Brothers, A., Freeman, B. J., Pingree, C., McMahon, W. M., Petersen, B., Jenson, W. R., \& Mo, A. (1991). Complex segregation analysis of autism. American Journal of Human Genetics, 29, 932-938.

Kaminsky, L., \& Dewey, D. (2001). Siblings relationships of children with autism. Journal of Autism and Developmental Disorders, $31,399-410$.

Kasari, C., \& Sigman, M. (1997). Linking parental perceptions to interactions in young children with autism. Journal of Autism and Developmental Disorders, 27, 39-57.

Keysor, C. S., \& Mazzocco, M. M. (2002). A developmental approach to understanding fragile $\mathrm{X}$ syndrome in females. Microscopy Research and Technique, 57, 179-186.

Knott, F., Lewis, C., \& Williams, T. (1995). Sibling interaction of children with learning disabilities: A comparison of autism and Down syndrome. Journal of Child Psychology, Psychiatry, and Allied Disciplines, 36, 965-976.

Krabbendam, L., Marcelis, M., Delespaul, P., Jolles, J., \& Van Os, J. (2001). Single or multiple familial cognitive risk factors in schizophrenia? American Journal of Medical Genetics, 105, 183-188.

Lainhart, J. E., \& Folstein, S. E. (1994). Affective disorders in people with autism: A review of published cases. Journal of Autism and Developmental Disorders, 24, 587-601.

Leaper, C. (2002). Parenting girls and boys. In M. H. Bornstein (Ed.), Handbook of parenting, Volume 1, 2nd edition (pp. 189-226). Mahwah, NJ: Lawrence Erlbaum.

Mazzocco, M. M. (2000). Advances in research on the fragile X syndrome. Mental Retardation and Developmental Disabilities Research Reviews, 6, 96-106.

Piven, J., Palmer, P., Jacobi, D., Childress, D., \& Arndt, S. (1997a). Broader autism phenotype: Evidence from a family history study of multiple-incidence autism families. American Journal of Psychiatry, 154, 185-190.

Piven, J., Palmer, P., Landa, R., Santangelo, S., Jacobi, D., \& Childress, D. (1997b). Personality and language characteristics in parents from multiple-incidence autism families. American Journal of Medical Genetics, 74, 398-411.

Poehlmann, J., Clements, M., Farsad, V., \& Abbeduto, L. (2003). Family experiences and maternal resolution of their child's diagnosis of fragile $X$ syndrome or Down syndrome. Paper presented at the 36th Annual Gatlinburg Conference on Research and Theory in Mental Retardation and Developmental Disabilities, Annapolis, MD.

Ritvo, E. R., Freeman, B. J., Mason-Brothers, A., Mo, A., \& Ritvo, A. M. (1986). Concordance for the syndrome of autism in 40 pairs of afflicted twins. American Journal of Psychiatry, 142, 74-77.

Rodrigue, J. R., Morgan, S. B., \& Geffken, G. (1990). Families of autistic children: Psychological functioning of mothers. Journal of Clinical Child Psychology, 19, 371-379.

Rodrigue, J. R., Morgan, S. B., \& Geffken, G. R. (1992). Psychosocial adaptation of fathers of children with autism, Down syndrome, and normal development. Journal of Autism and Developmental Disorders, 22, 249-263.

Rodrigue, J. R., Geffken, G. R., \& Morgan, S. B. (1993). Perceived competence and behavioral adjustment of siblings of children with autism. Journal of Autism and Developmental Disorders, $23,665-674$.

Roeyers, H., \& Mycke, K. (1995). Siblings of a child with autism, with mental retardation and with normal development. Child: Care, Health, and Development, 21, 305-319. 
Seltzer, M. M., Greenberg, J. S., Floyd, F. J., Pettee, Y., \& Hong, J. (2001). Life course impacts of parenting a child with a disability. American Journal on Mental Retardation, 106, 265-286.

Tager-Flusberg, H. (1999). An introduction to research on neurodevelopmental disorders from a cognitive neuroscience perspective. In H. Tager-Flusberg (Ed.), Neurodevelopmental disorders (pp. 3-24). Cambridge, MA: MIT Press.

Tsuang, M. T., Stone, W. S., \& Faraone, S. V. (2002). Understanding predisposition to schizophrenia: Toward intervention and prevention. Canadian Journal of Psychiatry, 47, 518526.

Wolf, L. C., Noh, S., Fisman, S., \& Speechley, M. (1989). Brief report: Psychological effects of parenting stress on parents of autistic children. Journal of Autism and Developmental Disorders, 19, 157-166.

Yeargin-Allsopp, M., Rice, C., Karapurkar, T., Doernberg, N., Boyle, C., \& Murphy, C. (2003). Prevalence of autism in a US metropolitan area. Journal of the American Medical Association, 289, 49-55. 